\title{
ANÁLISE DO DESEMPENHO DOS MUNICÍPIOS RECÉM-CRIADOS EM MINAS GERAIS A PARTIR DO ÍNDICE DE SUSTENTABILIDADE MUNICIPAL
}

\author{
Marcos Antônio Nunes \\ Fundação João Pinheiro, Belo Horizonte, MG, Brasil \\ Doutor em Geografia e Organização do Espaço \\ marcos.nunes@fjp.mg.gov.br \\ Ricardo Alexandrino Garcia \\ Universidade Federal de Minas Gerais - UFMG \\ Professor do Instituto de Geociências, Belo Horizonte MG, Brasil \\ alexandrinogarcia@gmail.com \\ Rodrigo Nunes Ferreira \\ Prefeitura de Belo Horizonte, Belo Horizonte, MG, Brasil \\ Doutor em Geografia \\ rodrigonunesferreira@gmail.com
}

\begin{abstract}
RESUMO
Ao se constatar o surto da criação de municípios no Brasil e, neste particular, em Minas Gerais, procurou-se avaliar e mensurar o grau de sustentabilidade alcançado pelas novas municipalidades mineiras. Inicialmente os municípios foram congregados em três categorias: "filhos", "mães" e "neutros". Em seguida, para avaliar a sustentabilidade dos municípios, foi utilizado o Índice de Sustentabilidade Municipal (ISM), um indicador sintético que reúne onze variáveis quali-quantitativas, congregadas em quatro dimensões: ambiental, social, econômica e institucional. Os resultados demonstraram que, dos 130 municípios recém-criados em Minas Gerais, apenas 45 deles apresentaram valores de ISM superiores aos registrados pelos respectivos municípios de origem. A partir daí procurou-se identificar quais foram as variáveis e as dimensões do indicador sintético que foram mais determinantes para que estes municípios lograssem êxito.
\end{abstract}

Palavras-chave: Criação de municípios. Minas Gerais. Indicadores socioeconômicos. Índice de Sustentabilidade Municipal.

\section{ANALYSIS OF THE PERFORMANCE OF NEW MUNICIPALITIES IN MINAS GERAIS FROM THE ÍNDICE DE SUSTENTABILIDADE MUNICIPAL}

\begin{abstract}
When it was verified the outbreak of the creation of municipalities in Brazil and, particularly, in Minas Gerais, sought to evaluate and measure the degree of sustainability reached by the new municipalities of Minas Gerais. Initially, municipalities were grouped into three categories: "filhos", "mães" and "neutros". Next, to evaluate the sustainability of municipalities, the Índice de Sustentabilidade Municipal (ISM) was used, a synthetic indicator that brings together eleven qualitative-quantitative variables, congregated in four dimensions: environmental, social, economic and institutional. The results showed that, of the 130 municipalities newly created in Minas Gerais, only 45 of them had ISM values higher than those recorded by the respective municipalities of origin. From this, it was possible to identify the variables and the dimensions of the synthetic indicator that were the most determinant for these municipalities to succeed.
\end{abstract}

Keywords: Creation of municipalities. Minas Gerais. Socioeconomic Indicators. Índice de Sustentabilidade Municipal. 


\section{INTRODUÇÃO}

Estão distribuídos pelo vasto território brasileiro 5.570 municípios. Este número poderia se ampliar, caso a ex-presidente Dilma Rousseff não vetasse o Projeto de Lei Complementar 416/2008 que possibilitaria a criação de centenas de municípios no final de 2013. Minas Gerais, há muito tempo, é o estado brasileiro mais fracionado, e atualmente possui 853 municípios -130 deles criados no último surto emancipacionista dos anos 1990.

Desde então surgiram várias pesquisas no Brasil procurando analisar a causa do fenômeno e as suas consequências; não apenas para os municípios que foram criados, mas também para os de origem.

As pesquisas que se referem à criação de municípios no Brasil são relativamente fartas, sobretudo quando se trata do Brasil República, notadamente a partir da Constituição Federal de 1988. Alguns autores são pioneiros ao estudar o fenômeno e suas primeiras consequências, imediatamente após o surto emancipacionista. Outros, posteriormente, têm realizado pesquisas no sentido de averiguar os impactos causados pelas emancipações, tanto para os municípios recém-criados quanto para os progenitores, com algumas manifestações contrárias ou favoráveis.

Favero (2004) identificou duas correntes que envolvem o tema emancipações. A primeira refere-se aos especialistas em economia, que geralmente estão vinculados às administrações públicas federais e estaduais, cuja visão é essencialmente administrativa e financeira. Eles são contrários por defender que o último processo de emancipações criou um excesso de municípios gerando tão somente aumento das despesas com as administrações públicas municipais nos dois poderes. A segunda é composta pelos favoráveis, que reconhecem a descentralização administrativa como principal virtude, e por promover a melhoria na distribuição das receitas públicas e o acesso aos serviços públicos urbanos a um maior número de pessoas.

Entre os que defendiam as emancipações explicitamente estão os trabalhos de Bremaeker (1991 e 1996), Noronha (1996) e outros. Por sua vez, as críticas mais contundentes realizadas, talvez, sejam as que foram feitas por Gomes e Mac Dowell (2000), que se pautaram pelo viés financeiro, analisando apenas os fatores relacionados à viabilidade econômica. Lorenzetti (2003) também se inclui nesta linha de pensamento. Poderia se pensar numa terceira corrente, daqueles que fazem uma análise das motivações e consequências das emancipações sem, contudo, tomar posição favorável ou contrária: Baracho (2000), Wanderley (2008), Pinheiro (2013), Nunes e Garcia (2014) e outros.

Em geral, o que esses trabalhos procuram demonstrar é a viabilidade econômica desses novos municípios, ou seja, como eles se autossustentariam. E também quais os diferentes impactos que causariam aos municípios remanescentes.

O caso mineiro é emblemático, pois o estado é o mais fracionado dentre as unidades da federação, e no último surto foram criados em sua grande maioria micromunicípios com menos de 5 mil habitantes. Excêntricas ainda são as formas poligonais resultantes após os fracionamentos territoriais, o que compromete o ordenamento territorial.

\footnotetext{
Esses sucessivos fracionamentos são em geral de caráter político, e por isso nem sempre são acompanhados de uma lógica que privilegia o ordenamento territorial, nem tampouco a distribuição da infraestrutura no território municipal. Isso compromete o acesso aos equipamentos urbanos e aos serviços municipais, além de alterar substancialmente a estética dos polígonos distritais, o que resulta em formas bizarras (OLIVEIRA et al., 2015, p. 238).
}

Devido à eclosão do número de municípios no país, o Congresso Nacional refreou o processo de emancipações distritais, ao editar a Emenda Constitucional no 15/1996 que estabeleceu 
novas exigências que deveriam constar em legislação federal para as emancipações distritais futuras. Entretanto, as emancipações distritais que foram efetivadas já tinham deixado consequências, e o que se observou foi o surgimento de inúmeros municípios, a maioria pobre, dependente do repasse do Fundo de Participação dos Municípios (FPM) e que apresentam indicadores socioeconômicos relativamente baixos (NUNES, GARCIA e OLIVEIRA, 2015).

Neste universo de municípios recém-criados, alguns deles lograram êxito, pois apresentaram nível de desenvolvimento que superaram o verificado em seu município de origem, como demonstraram Nunes, Lobo e Garcia (2018) e Nunes (2017a). Na pesquisa de Lobo, Nunes e Garcia (2018) a mensuração e comparação entre as categorias municipais se estabelece utilizando apenas o Índice de Desenvolvimento Humano (IDH). Já Nunes (2017a) desenvolveu um índice próprio, denominado Índice de Sustentabilidade Municipal (ISM), composto por 11 variáveis agregadas em 4 dimensões, que permite explorar aspectos do desenvolvimento e da sustentabilidade municipal, impossíveis de serem abordadas pelo universo informacional do $\mathrm{IDH}$.

Portanto, as questões centrais que se levantou inicialmente foram: 1) Como avaliar e mensurar o grau de sucesso dos municípios recém-criados através de um indicador sintético? e 2) Quais variáveis deste indicador podem explicar o êxito obtido por alguns municípios recém-criados? Estes são os objetivos principais desta pesquisa.

A partir desses questionamentos analisou-se os resultados do Índice de Sustentabilidade Municipal para os municípios mineiros, cuja metodologia e resultados serão resumidos nas próximas seções. A escolha de Minas Gerais se justifica por ser o estado brasileiro que detém o maior número de municípios, outro fator se refere a sua grande diversidade regional. Esta associação de fatores repercute diretamente nos resultados dos indicadores que serão analisados.

\section{QUANTIDADE X QUALIDADE: O FRACIONAMENTO TERRITORIAL E A NECESSIDADE DA MENSURAÇÃO}

Parece existir na natureza das análises humanas o desejo permanente de se opor a qualidade à quantidade, e neste aspecto os números oferecem este caráter seletivo. $E$ isso pode ser aplicado no caso do surto emancipacionista que ocorreu no Brasil, particularmente, em Minas Gerais.

Quando se questiona sobre a viabilidade econômica (orçamento e finanças) desses novos municípios, os emancipacionistas dizem que o aspecto econômico não pode ser supervalorizado na resolução de problemas humanos: acesso à saúde, educação, etc. Conforme observou o autor da lei que tratava sobre as emancipações distritais em Minas Gerais na década de 1990, o ex-deputado estadual José Braga: "Se apenas os distritos que geram renda puderem se emancipar, somente eles poderão receber FPM e, portanto, aumentarão cada vez mais as diferenças sociais nas regiões do Estado" (NUNES, 2001, p. 136).

A função social do FPM, para o ex-deputado, seria a de corrigir as deficiências e as insuficiências de determinadas regiões, que precisam sobreviver, e não conseguem fazer isso sem ajuda. José Braga considerava justa a preocupação nacional sobre a divisão do "bolo" do FPM para municípios, sem a contrapartida de crescimento destes recursos. E acrescenta: "quanto mais dividido, mais o FPM estará cumprindo sua função social" (NUNES, 2001, p. 136). Ao defender a descentralização administrativa, afirmava que o Brasil não pode parar o seu desenvolvimento pelo fato de os recursos federais não crescerem. Considerava mais frutífero questionar e combater as causas que impedem o aumento dos recursos do FPM, como a sonegação de impostos e a política tributária. 
No entanto, o que se viu nos últimos anos foi a corrida de prefeitos à capital federal pedindo mais recursos financeiros ao governo federal, sobretudo após a crise global de 2008. A crise econômica revelou que o municipalismo brasileiro não logrou êxito pela via da descentralização tributária, mediante transferência de mais recursos financeiros aos cofres municipais delegada pela Constituição Federal de 1988, a julgar pela permanente dependência do Município em relação ao governo federal. Isso demonstra que a descentralização política foi incompleta ou revela a necessidade de uma nova reforma político-administrativa que objetive a viabilidade dos municípios brasileiros (NUNES, 2017a).

A situação dos municípios tornar-se-ia mais grave ainda. Não bastasse a queda de arrecadação com a deflagração da crise econômica global, o governo federal executou políticas econômicas anticíclicas e de desoneração tributária para estimular determinados setores produtivos, como os produtos da linha branca, para manter os níveis de emprego e renda, e assim reduzir os efeitos da fraca atividade econômica. A medida repercutiu na queda do FPM, que é composto pelo Imposto sobre a Renda e Proventos de Qualquer Natureza (IR) e pelo Imposto sobre Produtos Industrializados (IPI), tributos afetados pela desoneração. Isso contribuiu para aprofundar a crise econômica, que atingiu, sobretudo, os municípios de menor porte, que têm no FPM sua principal receita orçamentária.

Não obstante o cenário econômico restritivo, ainda assim, comitivas e dirigentes políticos municipais pressionavam a Câmara dos Deputados para aprovarem a nova legislação referente às emancipações distritais. Aprovado pelos congressistas, a ex-presidente Dilma Rousseff vetou o Projeto de Lei Complementar 416/2008, que estipulava as novas regras para a criação, incorporação, fusão e desmembramento de Município, ao alegar que o governo federal não dispunha, em contrapartida, de recursos financeiros para compensar a redução do FPM que a medida traria. Apesar de o projeto apresentado para a sanção da ex-presidente ser mais rigoroso em relação às legislações passadas, como por exemplo ao exigir o retorno do Estudo de Viabilidade Municipal, ainda assim Dilma Rousseff manteve o veto (NUNES, 2017a).

É provável que o veto da ex-presidente tenha evitado a criação de pelo menos 300 novas municipalidades. Segundo estudo do Instituto de Pesquisa Econômica Aplicada (Ipea), seriam criadas no mínimo 363 novas cidades. Porém, esse dado deve ser muito maior, já que a pesquisa, que se baseou em pedidos de criação de municípios nas assembleias legislativas, não levou em conta os estados de Goiás, Mato Grosso do Sul, Rio de Janeiro, Roraima, Rio Grande do Sul, São Paulo e Tocantins. Na ocasião o Ipea não conseguiu obter os dados nas assembleias legislativas dessas unidades federativas (MARETTI, 2014).

Por isso é fundamental averiguar a qualidade das emancipações ocorridas após a Constituição Federal de 1988, estabelecendo medidas que possibilitem mensurar e comparar com as demais categorias municipais. Daí a importância dos indicadores, especialmente os relacionados à sustentabilidade municipal.

Neste particular, a permanente busca por indicadores de sustentabilidade tem sua origem na base estabelecida pela evolução dos indicadores empregados para fins de desenvolvimento econômico como, por exemplo, o Produto Nacional Bruto (PNB), o Produto Interno Bruto (PIB), etc. Nas últimas décadas, todavia, indicadores com fundamentos qualitativos passaram a ser empregados para uma análise mais ampla.

Destarte, a partir dos anos 1990 intensificou-se a criação de indicadores socioeconômicos com o objetivo de subsidiar avaliações sobre as condições de vida da população. Até então, o PIB, bem como o PIB per capita, eram francamente utilizados como proxy do nível de desenvolvimento socioeconômico dos cidadãos em diferentes países do mundo. Consolidavase entre os analistas de diversos campos do conhecimento o entendimento de que o PIB per capita não permitia mensurar de forma satisfatória a qualidade de vida, ou mesmo o nível de 
desenvolvimento de um país; observar apenas o crescimento do PIB não permitia visualizar as desigualdades sociais e econômicas que se consolidavam no interior desses países (STEFANI; NUNES; MATOS, 2014).

O PIB seria, então, paulatinamente substituído por outro indicador sintético, o IDH, que fora instituído pelo Programa das Nações Unidas para o Desenvolvimento (PNUD), em 1990, formulado pelo paquistanês Mahbud ul Haq com a colaboração do indiano Amartya Sen.

O IDH possibilita classificar e comparar, no longo prazo, o progresso alcançado pelos países, e contempla três dimensões: o nível educacional, a esperança de vida ao nascer, e o PIB per capita. É calculado como sendo a média dessas medidas, padronizada no intervalo de 0 a 1 . A partir deste indicador, os países passaram a ser classificados em: baixo IDH, quando inferior a 0,5; médio IDH, situados entre 0,5 e 0,8; e acima de 0,8, alto IDH (JANNUZZI, 2004, p. 121).

Outros indicadores, "inspirados" pelo IDH, foram construídos visando mensurar realidades e fenômenos específicos em diferentes países, regiões, cidades, etc.

\begin{abstract}
Se o IDH, sintetizando apenas três dimensões da realidade social, parece aos olhos de boa parte da mídia e gestores uma medida incontestável para monitorar o progresso social dos países [...], por que não desenvolver um indicador composto de um conjunto maior de proxies do mundo social e potencializar seu uso como ferramenta de avaliação mais ampla da ação pública e como critério de alocação global do gasto público no país? (SCANDAR NETO; JANNUZZI; SILVA, 2008, p. 2).
\end{abstract}

Atualmente é possível encontrar uma infinidade de indicadores e índices, dado a facilidade de acesso aos recursos computacionais e às bases de dados estruturadas; multiplicam-se as metodologias e propostas de indicadores sintéticos: de desigualdade, de vulnerabilidade social, de segregação socioespacial, etc. (PINHEIRO et al., 2008; NERI, 2006; RIBEIRO e GARCIA, 2005; JANNUZZI, 2004; VIEIRA, 2005).

A elaboração de uma medida simples e convincente não é uma tarefa fácil, e geralmente suscita inúmeras controvérsias. A questão que se coloca é sobre a possibilidade, alcance e oportunidade de se utilizar um indicador que internalize as questões teóricas associadas ao fenômeno em estudo, e que possua alta eficiência e seja de simples construção.

Desta feita, procurou-se adotar um indicador municipal que pudesse mensurar o grau de sustentabilidade alcançado pelas categorias municipais segundo o status do município em relação ao processo emancipatório. A sustentabilidade aqui entendida incorpora a noção de um tempo longo, que implica a "permanência", a "continuidade", a "viabilidade", assim dizendo, a própria garantia do futuro. A sustentabilidade, então, pode ser vista como a outra face da vulnerabilidade, à medida que a diminuição de uma acarreta o aumento da outra (HOGAN, MARANDOLA JR., OJIMA, 2010). No caso da "sustentabilidade municipal", enquanto condição de permanência ou viabilidade do Município, embora seja complexa e multideterminada, ela é passível de ser estimada através da operacionalização de indicadores quantitativos, como se descreve na próxima seção.

\title{
METODOLOGIA
}

Para avaliar e comparar os índices de sustentabilidade dos municípios mineiros foi preciso congregá-los em categorias municipais, segundo o status do município em relação ao processo emancipatório, após a Constituição Federal de 1988: municípios recém-criados ("filhos"), municípios remanescentes ("mães"), e municípios que não sofreram fracionamentos territoriais ("neutros"). A Figura 1 mostra os 853 municípios mineiros representados por polígonos que são 
os recortes municipais, e segundo as categorias municipais. Em destaque estão os municípios "filhos", em laranja, e os municípios "mães", em verde.

Figura 1 - Distribuição espacial dos municípios mineiros, segundo a categoria municipal: neutros, mães e filhos (2010).

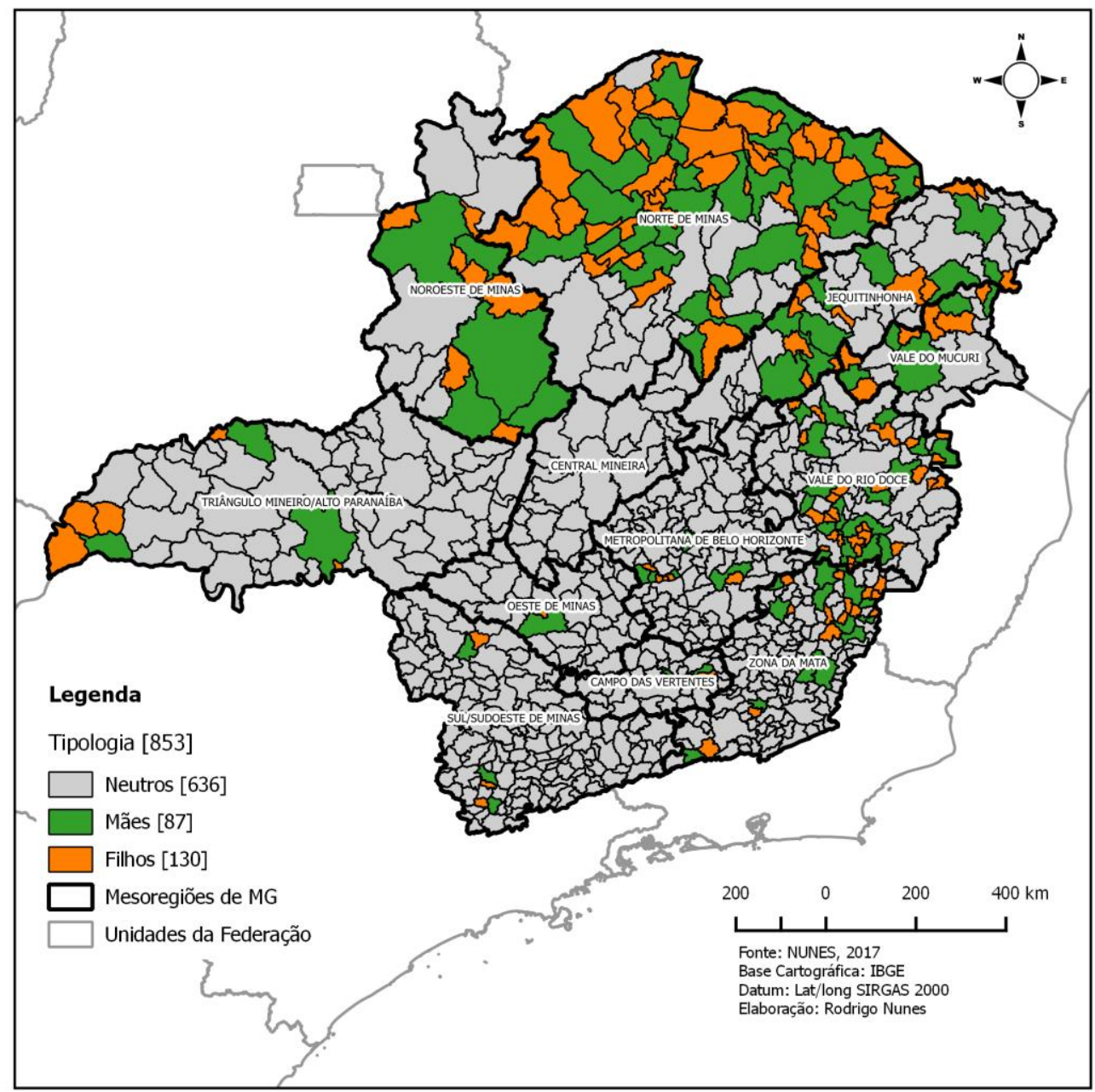

Fonte - NUNES (2017a).

Observa-se, na Figura 1, que a maior parte das emancipações ficou concentrada em algumas mesorregiões mineiras, notadamente as do norte e leste do estado. Essas emancipações refletiram não apenas o fato de serem os municípios mais setentrionais pouco fracionados, mas também a "pena" do legislador, que procurou favorecer a criação de novos municípios nas regiões mais pobres do estado.

Posteriormente, para mensurar o grau de sustentabilidade dos municípios mineiros, foi analisado os resultados do indicador sintético denominado Índice de Sustentabilidade Municipal (ISM), visando estabelecer comparações do grau de sustentabilidade entre as duas principais categorias municipais: os municípios recém-criados ou "filhos" e os municípios-mãe ou progenitores.

Conforme apresentado no Quadro 1, para a construção do ISM foram utilizados onze indicadores quali-quantitativos, distribuídos em quatro dimensões: social, econômica, ambiental e institucional - baseado no modelo Dashboard of Sustainability (VAN BELLEN, 2006). 
Quadro 1- Dimensões, subdimensões e indicadores para a construção do Índice de Sustentabilidade Municipal (ISM).

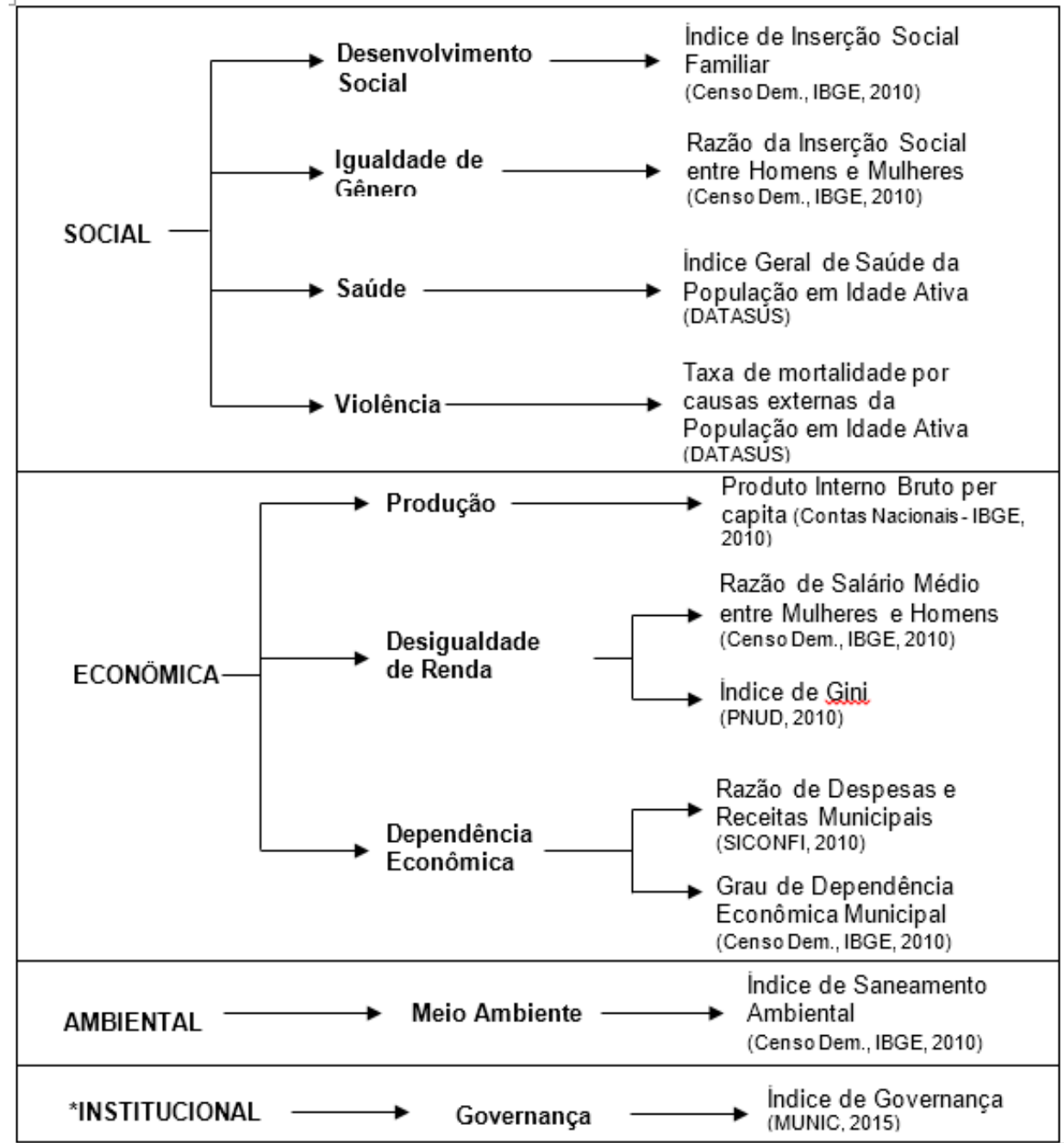

Fonte - Dados extraídos de: Censo Demográfico 2010 (IBGE), DATASUS, PNUD, (2010), SICONFI (2010), MUNIC 2015 (IBGE, 2016).

Em seguida, para efetuar a comparação do ISM dos municípios mineiros segundo as suas categorias, primeiramente foram identificados para cada um dos 130 municípios mineiros classificados como "filhos", a informação sobre o(s) respectivo(s) município(s) de procedência. Neste caso, utilizou-se como referência as informações sobre a legislação de implantação de municípios, disponível no relatório Evolução da Divisão Territorial do Brasil 1872-2010 (IBGE, 2011). Na sequência, foram comparados os valores de ISM dos municípios-mãe e dos respectivos municípios recém-criados, e também os códigos municipais do IBGE, para realizar o georreferenciamento.

Para a grande maioria dos municípios recém-criados no período, que tem como origem apenas um município, o valor do ISM do município de origem foi considerado como referência para o cálculo da diferença. Para os municípios que possuíam mais de uma origem, foi calculada uma média dos valores do ISM de todos os municípios de origem, e posteriormente a diferença entre o valor do ISM do município-filho e o valor médio do ISM de todos os municípios de origem (mães).

Por último, foram calculados os ISMs médios das mesorregiões mineiras para as categorias "mães" e "filhos". Apenas a Mesorregião Central Mineira não figurou dentre as que fracionaram seu território no período em análise. Em alguns casos, o ISM médio mesorregional da categoria "filhos" suplantou o da categoria "mães", conforme será analisado na próxima seção. 


\section{RESULTADOS E DISCUSSÃO}

Destarte, no período pós-Constituição de 1988, Minas Gerais passou a ter o seguinte retrato na divisão político-administrativa: 853 municípios; 636 não sofreram fracionamentos territoriais (“Neutros"); 87 deles (“Mães") geraram mais 130 novos municípios (“Filhos").

Os resultados do ISM (2010) apontam para uma semelhança com outros indicadores, notadamente o IDH. A julgar pela concentração dos valores mais baixos nas porções setentrional e nordeste do estado de Minas Gerais. Enquanto que os valores mais elevados do ISM estão concentrados nas porções centro-sul e Triângulo Mineiro, conforme mostra a Figura 2.

Figura 2 - Índice de Sustentabilidade Municipal (ISM) dos municípios mineiros, segundo as classes de valores (2010).

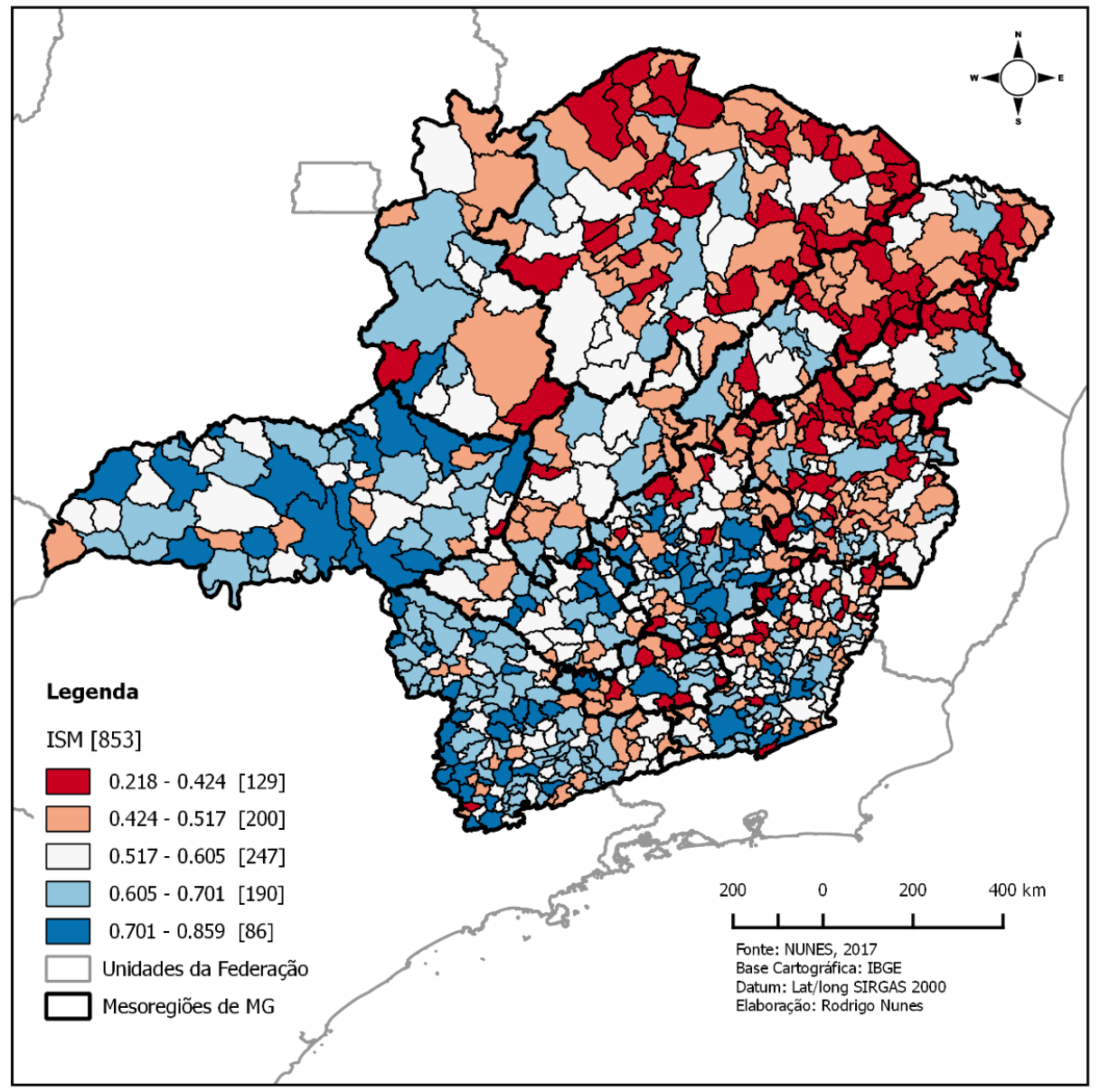

Fonte - NUNES (2017).

Os valores do ISM permitiram congregar os municípios em cinco classes: Sustentabilidade Alta-Alta, cujos valores variaram entre 0,701-0,859, e compreendeu aproximadamente $10 \%$ dos municípios mineiros, ou 86 deles; Sustentabilidade Alta-Baixa, com valores no intervalo de 0,605-0,701, e abrangeu 190 municípios. Com intervalo de 0,517-0,605 está a classe de Sustentabilidade Média, que englobou 247 municípios. No outro extremo estão as classes de menores valores, que totalizam $38,6 \%$ das municipalidades: Sustentabilidade Baixa, que apresentou um total de 200 municípios naquele ano, cujo intervalo foi de 0,424-0,517; e, por último a classe Sustentabilidade Crítica, cujos valores foram de 0,218-0,424, e representaram 129 municípios, conforme mostra a Figura 2.

Ao analisar, todavia, os valores do ISM médio por mesorregião e por categoria municipal, verifica-se, primeiro, que os municípios "neutros" apresentaram valores médios de ISM 
superiores aos da categoria "mães", e que, por seu turno, apresentou ISM superior ao da categoria "filhos", conforme mostra a Tabela 1.

Tabela 1 - Valores Médios do ISM por Mesorregiões e tipologia da situação de emancipação, Minas Gerais.

\begin{tabular}{l|c|c|c|c|c|c|c|c}
\hline \multirow{2}{*}{ Mesorregião } & \multicolumn{2}{|c|}{ Neutros } & \multicolumn{2}{c|}{ Mães } & \multicolumn{2}{c|}{ Filhos } & \multicolumn{2}{c}{ Total } \\
\cline { 2 - 10 } & Freq. & $\begin{array}{c}\text { Média } \\
\text { ISM }\end{array}$ & Freq. & $\begin{array}{c}\text { Média } \\
\text { ISM }\end{array}$ & Freq. & $\begin{array}{c}\text { Média } \\
\text { ISM }\end{array}$ & Freq. & $\begin{array}{c}\text { Média } \\
\text { ISM }\end{array}$ \\
\hline Campo das Vertentes & 32 & 0,528 & 2 & 0,574 & 2 & 0,577 & 36 & 0,534 \\
\hline Central Mineira & 30 & 0,548 & & & & & 30 & 0,548 \\
\hline Jequitinhonha & 30 & 0,447 & 10 & 0,503 & 11 & 0,453 & 51 & 0,459 \\
\hline Metrop. de Belo Horizonte & 92 & 0,573 & 6 & 0,589 & 7 & 0,628 & 105 & 0,578 \\
\hline Noroeste de Minas & 7 & 0,552 & 5 & 0,535 & 7 & 0,534 & 19 & 0,541 \\
\hline Norte de Minas & 20 & 0,502 & 24 & 0,492 & 45 & 0,450 & 89 & 0,473 \\
\hline Oeste de Minas & 42 & 0,606 & 1 & 0,594 & 1 & 0,448 & 44 & 0,602 \\
\hline Sul/Sudoeste de Minas & 140 & 0,619 & 3 & 0,648 & 3 & 0,741 & 146 & 0,622 \\
\hline Triâng. Mineiro/A. Paranaíba & 58 & 0,633 & 3 & 0,711 & 5 & 0,607 & 66 & 0,634 \\
\hline Vale do Mucuri & 12 & 0,423 & 5 & 0,450 & 6 & 0,407 & 23 & 0,425 \\
\hline Vale do Rio Doce & 60 & 0,501 & 15 & 0,488 & 27 & 0,478 & 102 & 0,493 \\
\hline Zona da Mata & 113 & 0,559 & 13 & 0,569 & 16 & 0,520 & 142 & 0,555 \\
\hline Total Geral & $\mathbf{6 3 6}$ & $\mathbf{0 , 5 6 7}$ & $\mathbf{8 7}$ & $\mathbf{0 , 5 2 7}$ & $\mathbf{1 3 0}$ & $\mathbf{0 , 4 9 2}$ & $\mathbf{8 5 3}$ & $\mathbf{0 , 5 5 1}$ \\
\hline
\end{tabular}

Fonte - Dados obtidos a partir da pesquisa de Nunes (2017a).

Quanto à média do ISM das mesorregiões mineiras, conforme mostram os dados da Tabela 1, a maioria se enquadra no grau de Sustentabilidade Média, seguida pela classe Sustentabilidade Baixa. Por sua vez, as mesorregiões Sul/Sudoeste de Minas e Triângulo Mineiro/Alto Paranaíba foram as únicas que apresentaram valores médios que se enquadraram na classe Alta-Baixa.

Enquanto a Mesorregião Central Mineira não teve nenhuma emancipação no período de análise, as mesorregiões Norte de Minas, Vale do Rio Doce, Zona da Mata e Jequitinhonha foram, pela ordem, as que apresentaram o maior número absoluto de fracionamentos municipais.

Embora a média geral do ISM para os municípios-filhos seja 0,035 ponto inferior à média para o grupo de municípios-mães, a simples comparação destes valores médios não permite afirmar que os municípios-filhos possuem valores inferiores aos municípios de origem. Para confirmar essa assertiva, faz-se necessário comparar par a par cada um dos municípios emancipados com o seu respectivo município de origem, conforme descrito na seção anterior.

Do total de 130 municípios mineiros classificados como "filhos", apenas 45 (34,6\%) apresentaram valores de ISM superior ao valor registrado para o(s) respectivo(s) município(s) de origem. Como resultado, na média, um município emancipado possui um valor de ISM 0,044 ponto abaixo do valor do município-mãe. Em termos de médias por mesorregiões mineiras, apenas nas do Sul/Sudoeste de Minas, Metropolitana de Belo Horizonte e Campo das Vertentes os valores médios da diferença entre o ISM dos "filhos" e "mães" são positivos, conforme mostra a Tabela 2.

Isso é um indicativo de que nessas mesorregiões do estado as emancipações distritais podem ter proporcionado desempenho melhor aos municípios criados. Entretanto, as três mesorregiões mencionadas, respondem apenas por 9,2\% dos municípios emancipados no período. Como regra, como pode ser observado na Figura 3, registrou-se para a grande maioria dos municípios-filhos, localizados nas mesorregiões do leste e norte do estado, um valor de ISM inferior ao do município de origem. 
Tabela 2 - Diferença média entre os valores do ISM dos municípios "filhos" e "mães", por mesorregião de Minas Gerais (2010).

\begin{tabular}{l|c}
\hline \multicolumn{1}{c|}{ Mesorregião } & $\begin{array}{c}\text { Diferença média no } \\
\text { ISM }\end{array}$ \\
\hline Sul/Sudoeste de Minas & 0,093 \\
\hline Metropolitana de Belo Horizonte & 0,040 \\
\hline Campo das Vertentes & 0,003 \\
\hline Noroeste de Minas & $-0,032$ \\
\hline Zona da Mata & $-0,043$ \\
\hline Vale do Mucuri & $-0,044$ \\
\hline Norte de Minas & $-0,049$ \\
\hline Vale do Rio Doce & $-0,059$ \\
\hline Jequitinhonha & $-0,062$ \\
\hline Triângulo Mineiro/Alto Paranaíba & $-0,098$ \\
\hline Oeste de Minas & $-0,146$ \\
\hline Central Mineira & - \\
\hline Total Geral & $-0,044$ \\
\hline
\end{tabular}

Fonte - NUNES (2017a).

Figura 3 - Diferença nos valores de ISM (2010) entre os municípios "filhos" e "mães" - MG.

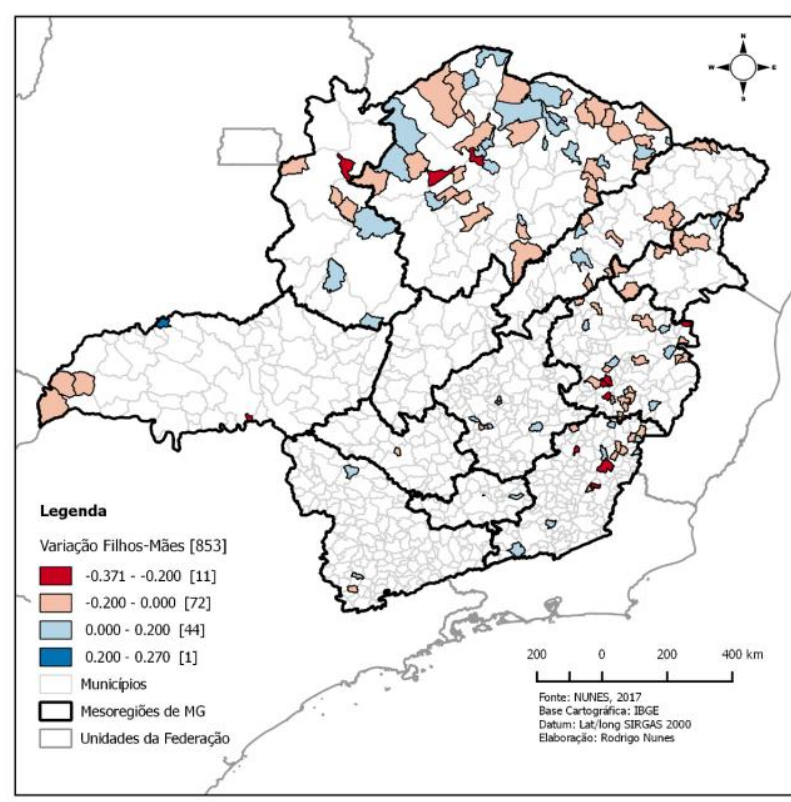

Fonte - NUNES (2017).

Mas, uma vez que se trata de um índice composto, uma segunda pergunta surge dos resultados apresentados acima: quais dos indicadores utilizados na composição do ISM melhor explicam essas diferenças encontradas entre "filhos" e "mães"?

Para responder a essa pergunta, optou-se por desenvolver uma abordagem inspirada na metodologia Distância P2 (DP2) desenvolvida por Pena (1977) para construção de indicadores sintéticos. O principal pressuposto dessa metodologia, e que aqui se faz uso, é o de que o peso de um indicador parcial em um índice final pode ser medido pela proporção de informação nova aportada pelo indicador ao modelo explicativo, medido pelo coeficiente de correlação múltiplo (R) (SOMARRIBA ARECHAVALA, 2008; PENA-TRAPERO, 2009). 
Para entender o impacto de cada indicador que compõe o ISM na diferença apurada entre municípios "mães" e "filhos", elaborou-se um modelo de regressão cuja variável dependente é a diferença no valor do ISM entre os municípios-filhos e "mães", e como variáveis explicativas o resultado do cálculo dessa mesma diferença entre as duas categorias para cada um dos 11 indicadores que compõem o ISM. Obviamente não faz sentido elaborar um modelo de regressão cuja variável dependente já é o resultado da combinação linear das variáveis explicativas. Por isso, inspirado na metodologia DP2, os resultados da regressão aqui explorados não são exatamente os coeficientes do modelo, mas o impacto que cada um dos 11 indicadores tem na conformação do potencial explicativo do modelo.

Para a construção do modelo final utilizou-se o Método Forward de inclusão de variáveis. Neste método, a entrada das variáveis previsoras é realizada uma a uma de acordo com o tamanho da sua contribuição na previsão do modelo, tendo como parâmetro de seleção de cada nova variável os índices de correlações semiparciais das variáveis restantes. Como resultado da aplicação do método, é possível construir um rank das variáveis com base no seu potencial de contribuição na melhoria da previsão do modelo, que pode ser expressa no percentual de elevação do valor do R-quadrado final promovida pela entrada da nova variável.

Os resultados, apresentados no Quadro 2, permitem comparar o peso original de cada um dos indicadores no ISM e a proporção de informação aportada pela entrada do indicador ao modelo explicativo final.

Quadro 2 - Resultados do modelo de regressão no Método Forward para explicação da diferença do ISM entre municípios "filhos" e "mães" a partir da diferença nos indicadores originais.

\begin{tabular}{|c|c|c|c|c|}
\hline $\begin{array}{l}\text { Ordem de } \\
\text { Inclusão }\end{array}$ & Variáveis inseridas & R-quadrado & $\begin{array}{l}\text { Peso do } \\
\text { Indicador } \\
\text { no ISM (\%) }\end{array}$ & $\begin{array}{l}\text { Proporção de } \\
\text { Informação } \\
\text { Aportada (\%)* }\end{array}$ \\
\hline 1 & $\begin{array}{l}\text { DIF-Dimensão da Gestão da } \\
\text { Governança }\end{array}$ & 0,506 & 25,0 & 50,7 \\
\hline 2 & DIF-Índice de Saneamento Ambiental & 0,888 & 25,0 & 38,3 \\
\hline 3 & $\begin{array}{l}\text { DIF-Índice Geral de Saúde população } \\
(15-59)\end{array}$ & 0,916 & 6,25 & 2,7 \\
\hline 4 & DIF-Produto Interno Bruto per capita & 0,931 & 5,0 & 1,5 \\
\hline 5 & $\begin{array}{l}\text { DIF-Participação das despesas } \\
\text { orçamentárias no total receitas }\end{array}$ & 0,946 & 5,0 & 1,5 \\
\hline 6 & $\begin{array}{l}\text { DIF-Óbitos causas externa/100milhab } \\
\text { população } 15 \text { a } 59 \text { anos }\end{array}$ & 0,958 & 6,25 & 1,2 \\
\hline 7 & DIF-Índice de Gini & 0,970 & 5,0 & 1,2 \\
\hline 8 & $\begin{array}{l}\text { DIF-Razão Média da Inserção Social } \\
\text { Familiar - mulheres e homens }\end{array}$ & 0,979 & 6,25 & 0,9 \\
\hline 9 & DIF-Inserção Social Familiar & 0,989 & 6,25 & 1,0 \\
\hline 10 & $\begin{array}{l}\text { DIF-Razão Média de salário } \\
\text { mulheres e homens }\end{array}$ & 0,993 & 5,0 & 0,4 \\
\hline 11 & $\begin{array}{l}\text { DIF-Participação dos rendimentos de } \\
\text { transferências no total de } \\
\text { rendimentos }\end{array}$ & 0,997 & 5,0 & 0,4 \\
\hline
\end{tabular}

Fonte - Nunes (2017a); dados trabalhados pelos autores.

Nota - *Contribuição da variável na previsão do modelo, expressa em percentual de elevação do valor do R-quadrado final decorrente da entrada da nova variável. 
Observa-se que somente a diferença entre os municípios "filhos" e "mães", no indicador da dimensão Gestão da Governança, é capaz de explicar mais de $50 \%$ da variação da diferença ente os "filhos" e as "mães" no valor do ISM, muito superior ao peso desse indicador na composição do ISM, que é de $25 \%$.

Outro indicador muito importante na explicação das diferenças entre os municípios "mães" e "filhos" é o Índice de Saneamento Ambiental, que responde por $38,3 \%$ do valor final do Rquadrado. Com exceção desses dois indicadores, todos os demais aportam no modelo explicativo da diferença entre "filhos" e "mães" no ISM uma parcela de informação inferior ao respectivo peso no ISM.

Conclui-se que os aspectos da gestão municipal sumarizadas nas dimensões Ambiental e Institucional são os mais relevantes na explicação do pior desempenho dos municípios-filhos no ISM, quando comparados aos municípios progenitores. E são justamente nessas dimensões que há um "pico de carência" (MAGALHÃES, 2008), que são representadas pelo setor de serviços das localidades de menor tamanho demográfico.

Conforme estudo realizado por Wanderley (2008), o autor demonstra que o comportamento de diversas variáveis socioeconômicas resultou na melhoria das condições sociais locais nos municípios emancipados em Minas Gerais, ao mesmo tempo que se observou que os municípios de origem tendem a não sofrer nenhum efeito estatisticamente significativo. Por isso, é preciso assegurar que as emancipações distritais não estimulem a destruição das bases econômicas do município a ser desmembrado (BARACHO, 2000), como ocorreu em Mateus Leme com a emancipação de Juatuba (NUNES, 2017b).

Essa discussão não é ponto pacífico entre os estudiosos do tema. Embora evidentes os avanços sociais observados entre as populações residentes nos pequenos municípios recémemancipados, alguns autores analisam apenas os fatores relacionados à viabilidade econômica. Para Gomes e Mac Dowell (2000), o processo de descentralização política permitiu a proliferação dos pequenos municípios e, dessa forma, acabou beneficiando as populações neles residentes. Todavia, os municípios pequenos nem sempre são os que detêm a população mais pobre. Além disso, são os pequenos e os micromunicípios que gastam mais por habitante com o Legislativo dos que os médios e os grandes. Desta forma, o ônus recai sobre os municípios proporcionalmente maiores, concluem os autores.

Portanto, o debate entre emancipacionistas e contrários estará sempre em pauta quando este tema voltar a ser discutido no Congresso Nacional. O Executivo e o Legislativo federais, entretanto, deveriam criar mecanismos que promovessem a melhoria dos indicadores sociais, em parceria com os estados e municípios, mesmo que isso incorra na supressão, fusão ou incorporação de municípios, e não apenas no fracionamento territorial representado pelas emancipações distritais.

\section{CONSIDERAÇÕES FINAIS}

No último surto emancipacionista dos anos 1990, Minas Gerais registrou a criação de 130 novos municípios, a maioria de pequeno porte e dependente do repasse do FPM. Dos atuais 853 municípios, foram identificados 636 que não sofreram desmembramentos e 87 municípios progenitores.

Neste contexto, alguns estudos surgiram visando demonstrar a viabilidade econômica dos municípios recém-criados, e como iriam se sustentar, além dos impactos que as emancipações causariam aos municípios de origem. Esta pesquisa, portanto, avaliou o nível de sustentabilidade alcançado por duas categorias de municípios em Minas Gerais: os recémcriados e os seus progenitores, ao comparar os seus respectivos Índices de Sustentabilidade Municipal (ISMs), para o ano de 2010.

A análise se baseou na identificação dos municípios recém-criados que apresentaram ISMs superiores aos dos respectivos municípios progenitores, e por esta razão lograram êxito, relativamente, em suas emancipações. A análise se concentrou nas mesorregiões mineiras para identificar possíveis padrões espaciais na distribuição dos municípios recém-criados exitosos. 
O ISM congrega 11 variáveis distribuídas em 4 dimensões. Foram identificadas, posteriormente, as variáveis que mais determinaram o incremento do indicador sintético dos municípios-filhos exitosos.

Calculados os valores dos ISMs, eles foram reunidos em cinco classes: Sustentabilidade AltaAlta. Sustentabilidade Alta-Baixa, Sustentabilidade Média, Sustentabilidade Baixa e Sustentabilidade Crítica. Identificou-se que a maioria das mesorregiões apresentaram ISM médio que se enquadra no grau de Sustentabilidade Média. As mesorregiões Sul/Sudoeste de Minas e Triângulo Mineiro/Alto Paranaíba foram as únicas que apresentaram valores médios que se enquadraram na classe Alta-Baixa.

A mesorregião Central Mineira foi a única que não teve nenhuma emancipação no período de análise, enquanto as mesorregiões Norte de Minas, Vale do Rio Doce, Zona da Mata e Jequitinhonha foram, pela ordem, as que apresentaram o maior número absoluto de fracionamentos municipais. A mesorregião Norte de Minas merece, contudo, um estudo à parte, não apenas pela quantidade absoluta de emancipações que nela ocorreram, mas também para averiguar a qualidade dessas emancipações, já que era o foco principal do legislador.

Ao analisar os valores do ISM médio por categoria municipal, verifica-se, primeiro, que em média os municípios "neutros" apresentaram valores superiores ao da categoria "mães" que, por seu turno, apresentou ISM superior ao da categoria "filhos". A média geral do ISM desta última categoria foi 0,035 pontos inferiores à média do ISM da categoria "mães". Todavia, foi necessário comparar par a par cada um dos municípios emancipados com o seu respectivo município de origem.

Os resultados apontaram que, do total de 130 municípios mineiros classificados como "filhos", apenas $45(34,6 \%)$ apresentaram valores de ISM superior ao valor registrado para o(s) respectivo(s) município(s) de origem.

Em termos de médias por mesorregiões mineiras, apenas nas do Sul/Sudoeste de Minas, Metropolitana de Belo Horizonte e Campo das Vertentes os valores médios da diferença entre o ISM de "filhos" e "mães" é positivo. Entretanto, essas mesorregiões responderam apenas por 9,2\% das emancipações ocorridas em Minas Gerais, no período em análise. Enquanto que na outra ponta estão as mesorregiões do leste e norte do estado, em que se registrou para a grande maioria dos municípios-filhos valores de ISM inferiores aos dos municípios de origem.

Observou-se que somente a diferença entre os municípios-filhos e "mães" dos indicadores da dimensão Gestão da Governança é capaz de explicar mais de $50 \%$ da variação da diferença ente os "filhos" e as "mães" no valor do ISM. Portanto, muito superior ao peso desse indicador na composição do ISM, de $25 \%$. Outro indicador importante na explicação das diferenças entre os municípios "mães" e "filhos" é o Índice de Saneamento Ambiental, que respondeu por 38,3\% do valor final do R-quadrado.

Por fim, os aspectos da gestão municipal sumarizadas nas dimensões Ambiental e Institucional são os mais relevantes na explicação do pior desempenho dos municípios-filhos no ISM, quando comparados aos municípios progenitores.

\section{REFERÊNCIAS}

BARACHO, M. A. P. Impactos da emancipação na arrecadação de ICMS dos municípios. Revista do Legislativo, Belo Horizonte, p. 57-66. abr./set. 2000

BRASIL. Emenda Constitucional № 15 de 12 de setembro de 1996. Dá nova redação ao $\S 4^{\circ}$ do art. 18 da Constituição Federal. Brasília, 1996. Disponível em: <http://www.senado.gov.br/atividade/const/con1988/EMC15_12.09.1996/EMC15.asp>. Acesso em: 21 abr. 2016.

BREMAEKER, F. E. J. Os novos municípios brasileiros. Revista Brasileira de Administração Pública, Rio de Janeiro, v. 38, n. 200, p. 82-92, jul./set. 1991. Limites à criação de novos municípios: a Emenda Constitucional № 15 . Revista 
Brasileira de Administração Pública, Rio de Janeiro, v. 43, n. 219, p. 118-128, abr./dez. 1996.

FAVERO, E. Desmembramento territorial: o processo de criação de municípios - avaliação a partir de indicadores econômicos e sociais. 278 f. Tese (Doutorado em Engenharia Urbana). São Paulo: Escola Politécnica da Universidade de São Paulo, 2004.

GOMES, G. M.; MAC DOWELL, M. C. Descentralização política, federalismo fiscal e criação de municípios: o que é mau para o econômico nem sempre é bom para o social. Brasília: IPEA, 2000. (Texto para discussão n. 706)

HOGAN, D. J.; MARANDOLA JR., E.; OJIMA, R. População e ambiente: desafios à sustentabilidade. São Paulo: Blucher, 2010. (Série Sustentabilidade, v. 1 / José Goldemberg, coord.)

IBGE - Instituto Brasileiro de Geografia e Estatística. Censo Demográfico 2010. Características da população e dos domicílios: resultados do universo. Rio de Janeiro: IBGE, 2011. Acompanha 1 CD-ROM.

Instituto Brasileiro de Geografia e Estatística. Evolução da divisão territorial do Brasil 1872-2010. IBGE, dez. 2011. Disponível em: <https://www.ibge.gov.br/home/presidencia/noticias/imprensa/ppts/0000000684181 $210201118380911960 . p d f>$. Acesso em: 29 jul. 2017.

Instituto Brasileiro de Geografia e Estatística. Perfil dos municípios brasileiros. Rio de Janeiro: IBGE, 2016.

IPEA - Instituto de Pesquisa Econômica Aplicada; SPI/MP - Secretaria de Planejamento e Investimentos Estratégicos. Objetivos de desenvolvimento do milênio: relatório nacional de acompanhamento. Brasília: Ipea: MP, SPI, 2007.

JANNUZZI, P. M. Indicadores sociais no Brasil: conceitos, fontes de dados e aplicações. 3. ed. Campinas-SP: Alínea, 2004.

LOBO, C. F. F.; NUNES, M. A.; GARCIA, R. Emancipações distritais mineiras e o grau de desenvolvimento humano. Belo Horizonte, 2018 (no prelo).

LORENZETTI, M. S. B. Criação, incorporação, fusão e desmembramento de municípios. Brasília, jul. 2003. (Consultoria Legislativa). Disponível em: <http://www2.camara.leg.br/acamara/documentos-e-pesquisa/estudos-e-notas-tecnicas/arquivos-pdf/pdf/305317. pdf $>$. Acesso em: 17 jun. 2017.

MAGALHÃES, J. C. Emancipação político-administrativa de municípios no Brasil. In: CARVALHO, A. X. Y.; ALBUQUERQUE, C. W.; MOTA, J. A.; PIANCASTELLI, M. (Orgs.). Dinâmica dos municípios. Brasília: IPEA, 2008. Cap. 1, p. 13-52. Disponível em: $<$ http://ipea.gov.br/agencia/images/stories/PDFs/ivros/Capitulo1_30.pdf>. Acesso em: 17 nov. 2018.

MARETTI, E. Para Ipea, projeto que permite criação de novos municípios aumenta desequilíbrios. Rede Brasil Atual, Política, 10 mar. 2014. Disponível em: <http://www.redebrasilatual.com.br/politica/2014/03/para-ipea-projeto-que-permite-criacao-denovos-municipios-aumenta-desequilibrios-3874.html>. Acesso em: 29 jul. 2017.

NERI, M. Desigualdade, estabilidade e bem-estar social. Rio de Janeiro: Fundação Getúlio Vargas, 2006. (Ensaios Econômicos)

NORONHA, R. Criação de novos municípios: o processo ameaçado. Revista de Administração Pública, Rio de Janeiro: IBAM, v. 43, n. 219, p. 110-117, abr./dez. 1996.

NUNES, M. A. Estruturação e reestruturações territoriais da região do Jequitinhonha em Minas Gerais. 2001. 206f. Dissertação (Mestrado em Geografia e Organização Humana do Espaço), Instituto de Geociências, Universidade Federal de Minas Gerais, Belo Horizonte, 2001. 
Emancipações distritais no Brasil e sustentabilidade: uma análise baseada no Índice de Sustentabilidade Municipal. 2017a. 219f. Tese (Doutorado em Geografia Humana), Instituto de Geociências, Universidade Federal de Minas Gerais, Belo Horizonte. (no prelo)

Criação de municípios no Brasil: motivações, vantagens e desvantagens. Revista Espinhaço: UFVJM, [S. I.], p. 11-20, out. 2017b. Disponível em: $<$ http://www.revistaespinhaco.com/index.php/journal/article/view/149>. Acesso em: 24 abr. 2018.

NUNES, M. A.; GARCIA, R. A. O municipalismo brasileiro e as emancipações distritais durante a década de 1990: o grau de sucesso mediante análise do IDH. In: Simpósio Mineiro de Geografia, Alfenas, maio 2014a. Disponível em: <http://www.unifalmg.edu.br/simgeo/system/files/anexos/Marcos\%20Ant\%C3\%B4nio\%20Nunes.pdf>. Acesso em: 10 set. 2014.

NUNES, M. A.; GARCIA, R. A.; OLIVEIRA, G. L. N. Emancipações distritais no Brasil após a Constituição Federal de 1988 e o potencial de captação de crédito dos municípios recémcriados. Anais do XVI ENANPUR: Espaço, Planejamento e Insurgências, Belo Horizonte, 2015. Disponível em: <http://xvienanpur.com.br/anais/?wpfb_dl=260>. Acesso em: 29 jul. 2017.

NUNES, M. A.; LOBO, C. F. F.; GARCIA, R. A. Emancipações distritais mineiras e o grau de desenvolvimento humano. Belo Horizonte, 2018 (no prelo).

OliVEIRA, G.; BAETA, A. M. M.; RODRIGUES, B. H. M.; NUNES, M. A.; MATOS, R. E. S. Proposta Metodológica para Identificação de vilas e povoados mineiros localizados mais próximos das sedes municipais de outros municípios vizinhos. Caderno de Geografia, Belo Horizonte, v. 22, n. 44, p. 237-255, 2015. https://doi.org/10.5752/P.2318-2962.2015v25n44p237

PENA, J. B. Problemas de la medición del bienestar y conceptos afines. INE, Madrid, 1977.

PENA-TRAPERO, BERNARDO. La medición del Bienestar Social: una revisión crítica. Estudios de Economía Aplicada, v. 27, n. 2, p. 299-324, ago. 2009.

PINHEIRO, T. C. A criação de municípios no Brasil nos períodos democráticos de 19461964 e pós-1988: uma abordagem espacial. 2013. 226 f. Tese (Doutorado em Geografia), Pontifícia Universidade Católica de Minas Gerais, Belo Horizonte, 2013.

PINHEIRO, L.; FONTOURA, N. O.; QUERINO, A. C.; BONETTI, A.; ROSA, W. Retrato das desigualdades de gênero e raça. 3. ed. Brasília: IPEA: SPM: UNIFEM, 2008.

PNUD - Programa das Nações Unidas para o Desenvolvimento. 2010. Disponível em: <http://www.br.undp.org/content/brazil/pt/home/idh0/rankings/idhm-municipios-2010.html>. Acesso em: 15 ago. 2017.

RIBEIRO, A.; GARCIA, R. A. Segregação socioespacial em Belo Horizonte: uma aplicação de modelos difusos. Geografias, Belo Horizonte, v.1, n.1, p. 86-97, jul./dez. 2005.

SCANDAR NETO, W. J.; JANNUZZI, P. M.; SILVA, P. L. N. Sistemas de indicadores ou indicadores sintéticos: do que precisam os gestores de programas sociais? In: XVI Encontro Nacional de Estudos Populacionais. Caxambu, 29 set. a 3 out. 2008. Disponível em: $<$ http://www.abep.nepo.unicamp.br/encontro2008/docsPDF/ABEP2008_1511.pdf>. Acesso em: 12 set. 2016.

SEN, A. Desenvolvimento como liberdade. Tradução Laura Teixeira Motta. São Paulo: Companhia das Letras, 2010.

A ideia de justiça. Tradução Denise Bottmann e Ricardo Doninelli Mendes. São Paulo: Companhia das Letras, 2011.

SICONFI - Sistema de Informações Contábeis e Fiscais do Setor Público Brasileiro. Disponível em: <https://siconfi.tesouro.gov.br/siconfi/index.jsf>. Acesso em: 15 ago. 2017.

SOMARRIBA ARECHAVALA, M. N. Proximación a la medición de la calidad de vida social e individual en la Europa Comunitaria. Tese doutorado, Universidad de Valladolid, 2008. 
STEFANI, J.; NUNES, M. A.; MATOS, R. Índice Mineiro de Responsabilidade Social e sua dinâmica na região de planejamento Jequitinhonha/Mucuri. Caderno de Geografia, Belo Horizonte, v. 24, n. 41, p. 17-33, jan./jun., 2014.

VAN BELLEN, H. M. Indicadores de sustentabilidade: uma análise comparativa. 2. ed. Rio de Janeiro: Editora FGV, 2006.

VIEIRA, A. B. O lugar de cada um: indicadores sociais de desigualdade intraurbana. 2005. $157 \mathrm{f}$. Dissertação (Mestrado em Geografia). Universidade Estadual Paulista, Presidente Prudente, 2005. Disponível em: <http://www2.fct.unesp.br/pos/geo/dis_teses/05/05_alexandre.pdf>. Acesso em: 4 jul. 2017.

WANDERLEY, C. B. Emancipações municipais mineiras ocorridas na década de 90: estimativa de seus efeitos sobre o bem-estar social. In: Anais do XIII Seminário Sobre Economia Mineira, Diamantina, Cedeplar, 2008.

Recebido em: 30/08/2018

Aceito para publicação em: 21/12/2018 